\title{
Factors Affecting University Library Website Design
}

Existing studies have extensively explored factors that affect users' intentions to use university library website resources (ULWR); yet little attention has been given to factors affecting university library website design. This paper investigates factors that affect university library website design and assesses the success of the university library website from both designers' and users' perspectives.

The findings show that when planning a website, university web designers consider university guidelines, review other websites, and consult with experts and other divisions within the library; however, resources and training for the design process are lacking. While website designers assess their websites as highly successful, user evaluations are somewhat lower. Accordingly, use is low, and users rely heavily on commercial websites. Suggestions for enhancing the usage of ULWR are provided.

$F^{2}$ rom a utilitarian perspective, a website evaluation is based on users' assessments of the website's instrumental benefits. ${ }^{1}$ If a website helps users complete their tasks, they are likely to use the website. Following this line of reasoning, dominant research has reported that users are most likely to use university library website resources (ULWR) when they can help with user tasks. ${ }^{2}$ Although we know now that the utilitarian perspective should be applied to web design, not clear is the extent to which web designers consider users' needs and, likewise, the extent to which users consider ULWR to be successful in terms of meeting their needs. Also not clear are what factors other than user needs influence university library website design. This is not a trivial issue because university libraries have invested a massive number of resources into providing web services and need to justify their investments to stakeholders (such as the university) by demonstrating their ability to meet users' needs. ${ }^{3}$ Also important is the identification of these factors because web design and website performance are closely correlated. ${ }^{4}$ As a consequence, investigating factors that influence successful university library website design and providing managerial guidance is a timely pursuit. Later, the objectives of this paper are twofold:

1. What factors influence university library website design?

2. To what extent do website designers and users consider the university library website to be successful?

To explore these research questions, this study identifies factors influencing university library website design that have been reported in existing literature. These factors include usability testing and institutional forces. ${ }^{5}$ Because website design studies are sparse, this study examines the success of technology utilization studies to further identify factors that are pertinent to website design in order to provide a comprehensive view of web design success factors.

A review of literature related to university library website design will be offered in the next section. The research methods, which discuss the data collection strategies and the measurements used in the current study, will be followed by the literature review. The findings of the study will later be reported and discussed after the research methods section. The paper will then conclude with an overview of the implications the findings have for academia and managers.

\section{Literature Review}

This section offers an overview of the existing website design literature and relevant success factors. These factors include institutional forces, supervisors' technical knowledge and support, input from secondary sources, and input from users. Because the aforementioned elements are identified as independent variables, this study also adopts them as such. Following existing studies, website success factors are identified from the utilitarian perspective. ${ }^{6}$ The dependent variables are (1) the extent to which website designers meet users' needs, (2) the extent to which users perceive ULWR to be useful, and (3) their actual usage. In this manner, the evaluation of success is measured from different perspectives. This discussion of the independent and the dependent variables appears in the conceptual model, figure 1.

\section{Institutional Forces}

Institutional forces refer to as organizations following other organizations practices to secure efficiency and legitimacy. Existing studies have identified three institutional forces: coercive, mimetic, and normative. ${ }^{7}$ Coercive force takes place when an organization pressures others to adopt a certain practice. It is higher when an organization is a subset of another organization. In this research context, the university could be an agent of coercive force. Mimetic force refers to organizations following other organizations' practices, and it is especially common for organizations within the same industry group. ${ }^{8}$ Because organizations within

Yong-Mi Kim (yongmi@ou.edu) is Assistant Professor, School of Library and Information Studies, University of Oklahoma, Tulsa, Oklahoma. 


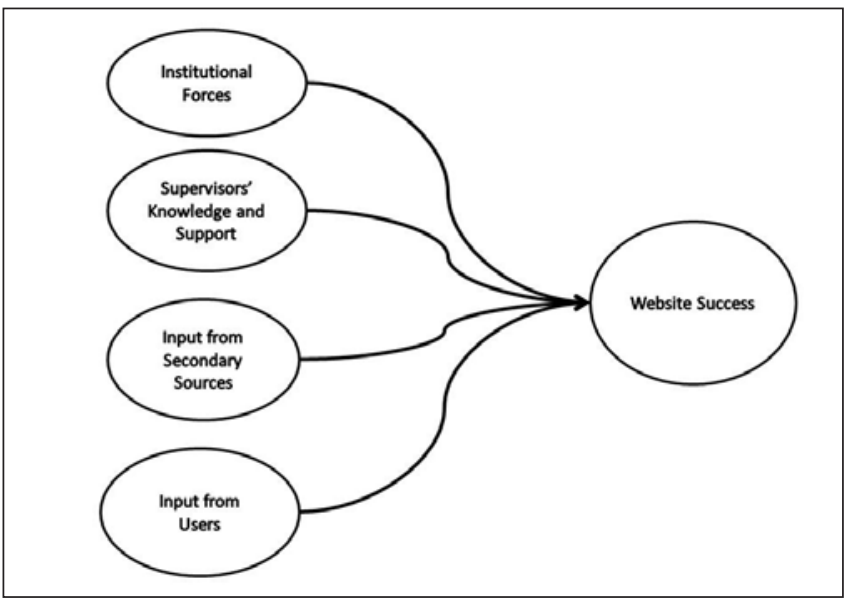

Figure 1. Conceptual Model for Website Design Success

the same industry face similar problems or issues, mimetic decisions can reduce uncertainty and secure legitimacy. ${ }^{9}$ In this context, website designers may analyze and emulate other universities' websites to claim that their websites are congruent with successful websites, thereby justifying their managerial practices. Normative force is associated with professionalism..$^{10}$ Normative force occurs when the norms (e.g., equity, democracy, etc.) of the professional community are integrated into organizational decision-making. In a library setting, website designers may follow a set of value systems or go to conferences to discover ways to better deliver services.

There is evidence that website designers follow other organizations. ${ }^{11}$ This phenomenon is known as isomorphism. The appearance and the structure of websites show isomorphic patterns when an organization follows examples of other organizations' websites or conforms to institutional pressures. ${ }^{12}$ Another study reports coercive forces in the design of university library websites; the parent institution exercises power over library website design by providing guidelines, and later, the design is not independent. ${ }^{13}$

\section{Supervisors' Technical Knowledge and Support}

Literature on supervisors' knowledge of and support for technology has long been recognized as one of the most important technology success factors. ${ }^{14}$ If supervisors are knowledgeable about technology, they are likely to support and provide resources for training. ${ }^{15}$ Supervisors' technical knowledge also serves as a signal for the importance of the utilization of technology within the organization; consequently, employees actively look for ways to utilize technology and vigorously adopt technology. ${ }^{16}$
Although it is a critical factor for website success, there is little evidence that website designers receive strong support from their supervisors. Research shows that supervisors' lack of knowledge about websites inhibits user-centered website design. ${ }^{17} \mathrm{~A}$ respondent from Chen et al.'s study reports, "It's really a pain trying to connect with our administration on the topic of Web design and usability, because even definitions are completely out the window" and "the dean and the associate directors know little about the need for usability and view it as a last minute check-off, so they can say that the Web site is tested and usable."18 Lack of supervisor support inhibits website usability. ${ }^{19}$

\section{Input from Secondary Sources}

Website designers typically aggregate information from secondary sources rather than from users. Identified secondary sources are consultations with experts, other divisions within the library, webmasters, web committees, and focus groups. ${ }^{20}$ The most widely used method is consultation with experts. ${ }^{21}$ Experts uncover technical flaws and any obvious usability problems with a design, ${ }^{22}$ facilitate focus groups, ${ }^{23}$ and create new information architecture ${ }^{24}$ Because they are experts, however, their ways of thinking may not be the same as users. ${ }^{25}$ Research shows that 43 percent of the problems found by expert evaluators were actually false alarms and that 21 percent of users' problems were missed by those evaluators. If this analysis is true, expert evaluators tend to miss and incorrectly identify more problems than they correctly identify; ${ }^{26}$ consequently, expert testing should not substitute for user testing. ${ }^{27}$ Another problem with secondary sources is that web committees "are ignorant about integrating design with usability and focus on their own agenda." 28 Nonetheless, because of the lack of available resources to conduct more rigorous usability tests and the difficulty of collecting information directly from users, secondary sources such as expert evaluations are commonly used. ${ }^{29}$

\section{Input from Users}

User input provides a great advantage for directly finding out users' needs and integrating a user-centered design during the development stage. ${ }^{30}$ Often, information from secondary sources makes assumptions about users' needs. ${ }^{31}$ To discover users' genuine needs, designers can conduct a regular user survey and/or seek out users' input. $^{32}$ By surveying users' needs, one can overcome criticism such as, "most websites are created with assumptions of more expert knowledge than the users may actually possess," and can address users' needs more effectively. ${ }^{33}$ Discovering users' needs goes beyond usability testing because information obtained directly 
from users will reveal what users want and what should be done to meet their needs, thereby enhancing ULWR usage. However, research shows that this aspect is not actively integrated into web design due to the lack of support from supervisors. ${ }^{34}$

\section{Website Success}

Success can be measured according to the website's purpose: to what extent does the website meet users' needs? In the university library website context, following a utilitarian perspective, researchers measured the success by the degree of ULWR integrated into users' tasks and users' frequent visits to the website. ${ }^{35}$ These two measurements, when combined with the designers' perceptions of success, will allow one to measure the users' and designers' perspectives of website success. By measuring from these two sides, if there is a discrepancy between the two success outcomes, it will prompt designers to adjust their viewpoints to align their success measures with users.

\section{Research Methods}

This section discusses the sampling strategies and the measurements for the independent and the dependent variables. Because one of the contributions of this study is to compare users' and designers' perceptions of website success, the samples are drawn from two groups: one is from university library website designers and the other one is from university library users. For the designer side, it is directly collected from university library website designers; later, libraries without website designers within the library are excluded. The designer sample is identified from the publicly available Yahoo academic library list (http:/ / dir.yahoo.com/ reference/libraries). The list contains 448 academic libraries, including those outside the United States. The research assistant made a phone call to the libraries that reside in the United States and verified the existence of website designers within the library, which included 86 academic libraries. If a library had a website designer, the research assistant contacted the person and invited him or her to participate in the study. Because of difficulties contacting website designers, the research assistant was able to collect 16 responses between May 2009 and February 2010. Once the graduate assistant identified the unreachable designers, the researcher e-mailed those designers between January and April of 2010 and added 30 more responses to the dataset, which resulted in a total of 46 responses (a 54 percent response rate). For the user side, a survey questionnaire was sent to faculty, doctoral, master's, and undergraduate students between
March and May 2009. A total of 315 responses were collected (139 males and 176 female; 148 undergraduates, 101 master's, and 66 doctoral/faculty; Business 152, Human relations 51, Psychology 43, Engineering 41, Education 20, Other 8). Because detailed discussion of the user side of this sample appears elsewhere, ${ }^{36}$ it will not be repeated here to avoid redundancy.

Because sparse research has been done in this area, the questionnaire and its measurements were created based on literature relating to the successful deployment of technology, but they were modified to fit into the website design context. Because of this modification, the finalized instrument was pretested and pilot tested before use in this study. ${ }^{37}$

The institutional forces are measured in three categories: coercive isomorphism (i.e., following the university guidelines regarding website creation), mimetic isomorphism (i.e., investigating other university websites and investigating commercial websites), and normative isomorphism (i.e., attending conferences). Following existing studies, supervisors' knowledge and support are assessed by the web designer in two areas: the extent to which a supervisor is knowledgeable about technology and aware of the importance of technology. The supervisor's support for the website is measured by asking web designers about the extent to which their supervisors allocated resources and offered training. Input from secondary sources is measured by asking the extent to which website designers consult sources such as experts, other divisions, webmasters, and web committees. Input from users is measured by the extent to which web designers collect information from website users. Finally website successes are measured by two categories: assessments made by the web designers and the website users themselves. The finalized measurements and the sources appear in table 1.

\section{Report of Findings}

This section reports the empirical findings of each category discussed in the previous section. Figure 2 shows institutional forces that influence university library website design. The first category is coercive force, the second category is mimetic forces, and the third category is normative force. It is clear that the majority of university library web designers (75 percent) comply with the guidelines given by the university, which is a measurement of coercive force; and also designers investigate other universities' websites (75 percent) and commercial websites (59 percent), which is a measurement of mimetic forces; however, designers don't appear to actively attend conferences that influence website design, which is a measurement of normative force. 
Table 1. Instrument

\begin{tabular}{|c|c|c|}
\hline Construct & Operationalization & Source \\
\hline Institutional forces & $\begin{array}{l}\text { Following university guidelines regarding website creations } \\
\text { Investigating other university websites } \\
\text { Investigating commercial websites } \\
\text { Attending conferences }\end{array}$ & $11,12,15$ \\
\hline $\begin{array}{l}\text { Supervisor's } \\
\text { technical knowledge } \\
\text { and support }\end{array}$ & $\begin{array}{l}\text { Supervisor's knowledge about technology } \\
\text { Supervisor's evaluation of the importance of technology } \\
\text { Supervisor's evaluation of the importance of website utilization } \\
\text { Availability of website tools } \\
\text { Availability of budgeting } \\
\text { Availability of technical training } \\
\text { Availability of website creation training }\end{array}$ & 17,22 \\
\hline $\begin{array}{l}\text { Input from secondary } \\
\text { sources }\end{array}$ & $\begin{array}{l}\text { Consulting with experts } \\
\text { Consulting with other divisions within the library } \\
\text { Consulting with webmasters } \\
\text { Consulting with website committee } \\
\text { Consulting with focus group }\end{array}$ & $10,25-26$ \\
\hline Input from users & $\begin{array}{l}\text { Conducting user survey } \\
\text { Utilizing users' inputs }\end{array}$ & 10 \\
\hline $\begin{array}{l}\text { Website success } \\
\text { measures from web } \\
\text { designer }\end{array}$ & $\begin{array}{l}\text { We meet users' needs } \\
\text { We provide better services via the website } \\
\text { We satisfy users' needs } \\
\text { We provide quality services } \\
\text { Our library is overall successful }\end{array}$ & 1,2 \\
\hline $\begin{array}{l}\text { Website success } \\
\text { measures from } \\
\text { website users }\end{array}$ & $\begin{array}{l}\text { It lets me finish my project more quickly } \\
\text { It helps improve my productivity } \\
\text { It helps enhance the quality of my project } \\
\text { The extent to which users integrate website library resources into users' tasks* } \\
\text { Frequency of users' visits to university library website }\end{array}$ & $3,41,43$ \\
\hline
\end{tabular}

All items are measured with a Likert scale: 1 not really; 2: somewhat; and 3: greatly.

* measured by percentage

${ }^{* *}$ measured by frequency

The second group of factors that affects website design is supervisors' knowledge about technology and support for the utilization of technology (see figure 3). Web designers have a somewhat mixed perception about their supervisors' technical knowledge. More specifically, 37 percent of respondents responded that their supervisors do not have good knowledge about technology; 23 percent responded that their supervisors were somewhat knowledgeable about technology; and 40 percent responded that their supervisors have good knowledge about technology; thus, web designers have mixed evaluations about supervisors' technical knowledge. Web designers reported that their supervisors' perceptions of the importance of technology and websites are higher than their technical knowledge. Approximately 60 percent of designers responded that their supervisors emphasize the importance of technology and websites, and the remaining respondents answered that their supervisors are somewhat aware of the importance or do not value it at all.

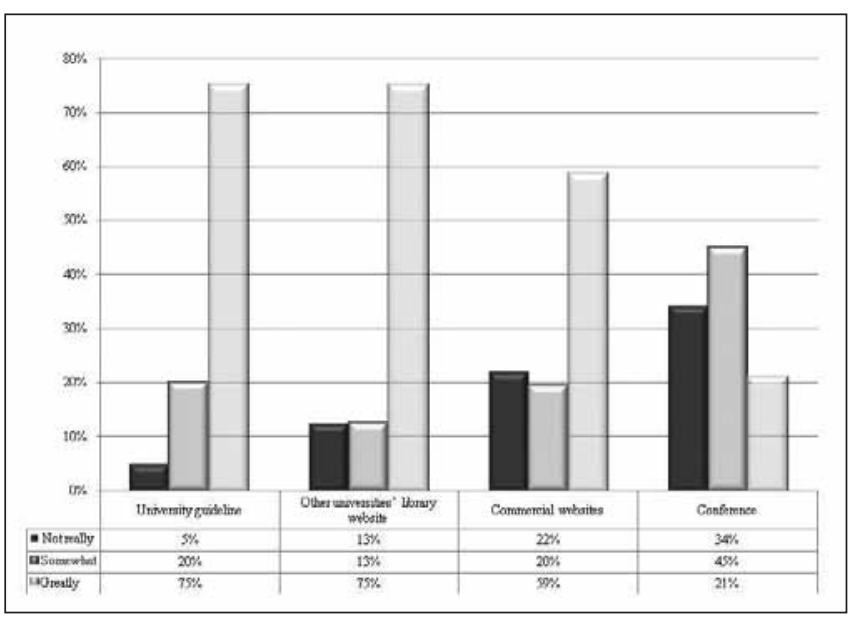

Figure 2. Institutional Forces 


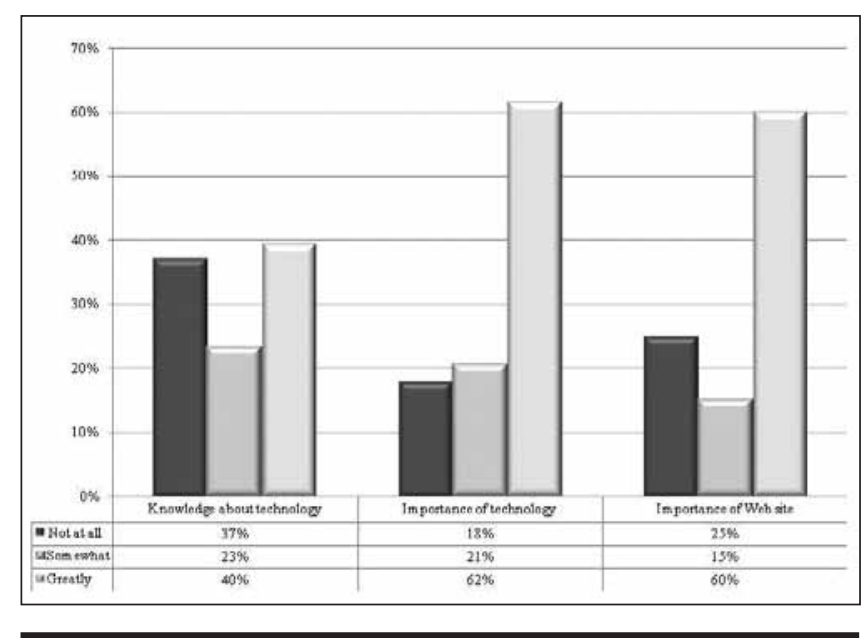

Figure 3. Supervisor's Knowledge about Technology

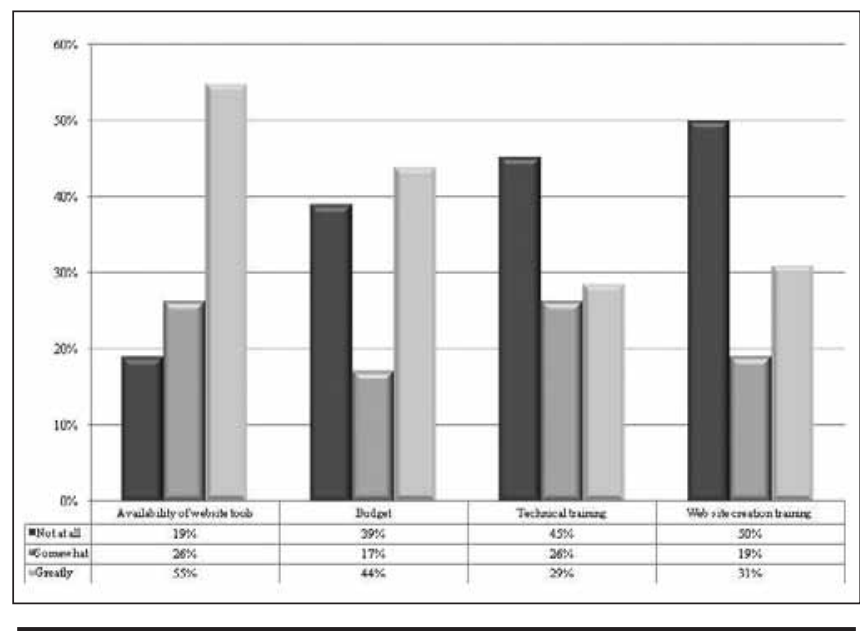

Figure 4. Supervisor's Support

Figure 4 shows the extent to which supervisors support web designers. Fifty-five percent of respondents reported that they have good web creation tools; 44 percent responded that they have enough budget for website creation, and almost a similar rate of respondents (39 percent) reported that they do not have adequate budgets for website creation. The last two questions concerning training show somewhat different results from the findings of the first two questions. The majority of web designers do not get technology-related or website creation-related training. Less than one-third of respondents reported that they receive enough technology-related and web creationrelated training.

The findings of the use of secondary sources show in figure 5 that web designers actively leverage such information sources for web design. By category, over 80

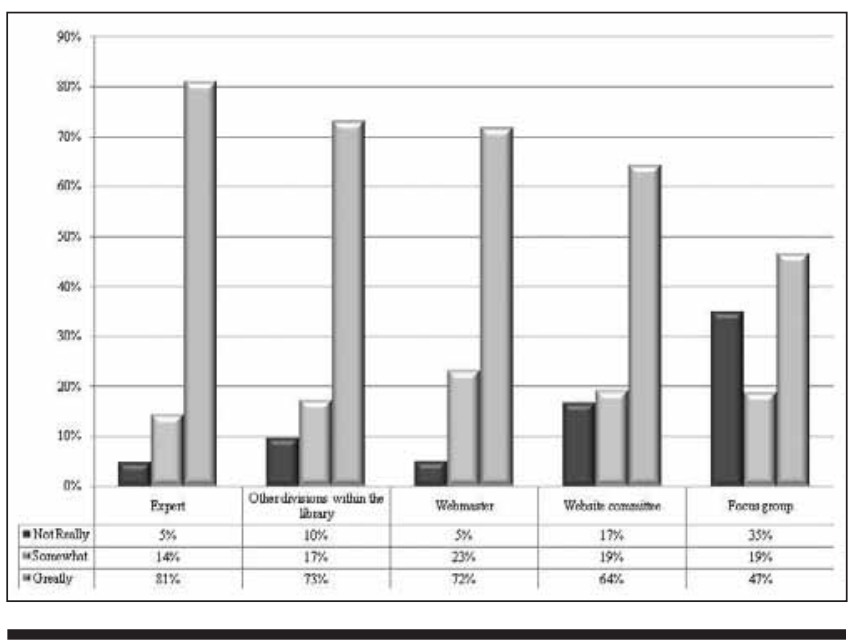

Figure 5. Input from Secondary Sources

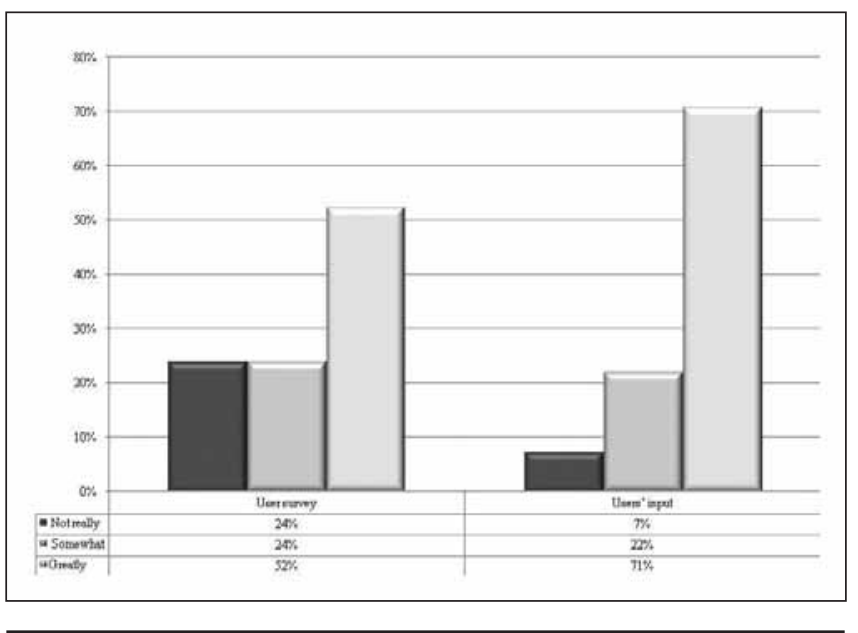

Figure 6. Input from Users

percent of respondents reported that they consult with web experts; over 70 percent responded that they integrate input from other divisions; and around 70 percent consult with webmasters. The utilization of secondary information sources for website creation is very high except for focus groups. The most widely used technique in this category is expert consultations followed by consultations with other divisions within the library. Web designers also consider input from webmasters and web committees.

Figure 6 shows the extent to which website designers apply input directly derived from web users. Around half of respondents reported that they obtain information from user surveys, and around 70 percent responded that they consider users' input collected via comments, feedback, and complaints. 


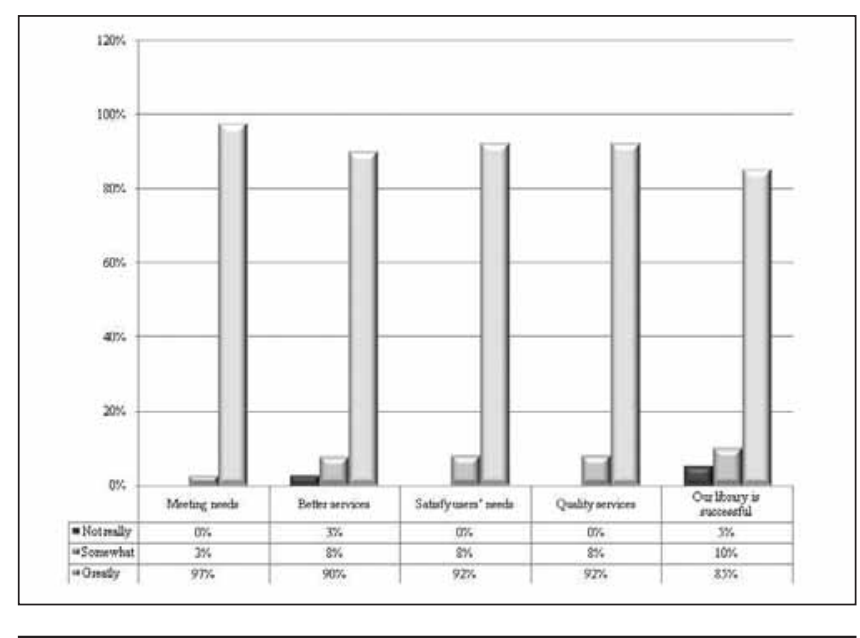

Figure 7. Website Success Evaluated by Design

\section{Website Success}

Website success is evaluated from two sides: designer opinion and user opinion. Overall, designers evaluated their websites to be highly successful. They believe that they meet users' needs, provide better services via the web, satisfy users' needs, and provide quality services. Later, their evaluation of their website is extremely positive, as reported in figure 7.

Figure 8 shows users' perceptions of the usefulness of ULWR. Users generally agree that ULWR are useful for their academic projects. More specifically, 55 percent responded that they are able to finish their tasks quickly because of the resources; 65 percent reported that they could increase their productivity; and 67 percent responded that they enhanced project quality thanks to the resources. On the other hand, a significant portion of respondents (more than 30 percent) do not think or have no opinions that ULWR are useful for their academic tasks.

Figure 9 investigates how often users visit university library websites. Approximately 30 percent reported that they never visited or rarely visited the university library website. Thirty-two percent made a visit to the website a couple of times a month, and approximately 40 percent visited the library website a couple of times a week or daily.

Figure 10 examines the users' utilization of ULWR versus commercial website resources. The responses from 315 users show that they utilize commercial websites more than ULWR. Specifically, 46 percent of respondents reported that they use less than 20 percent of ULWR and only 8 percent utilize ULWR more than 80 percent. In contrast, 14 percent utilize less than 20 percent of commercial website resources, and 22 percent utilize more than 80 percent of commercial website resources. The

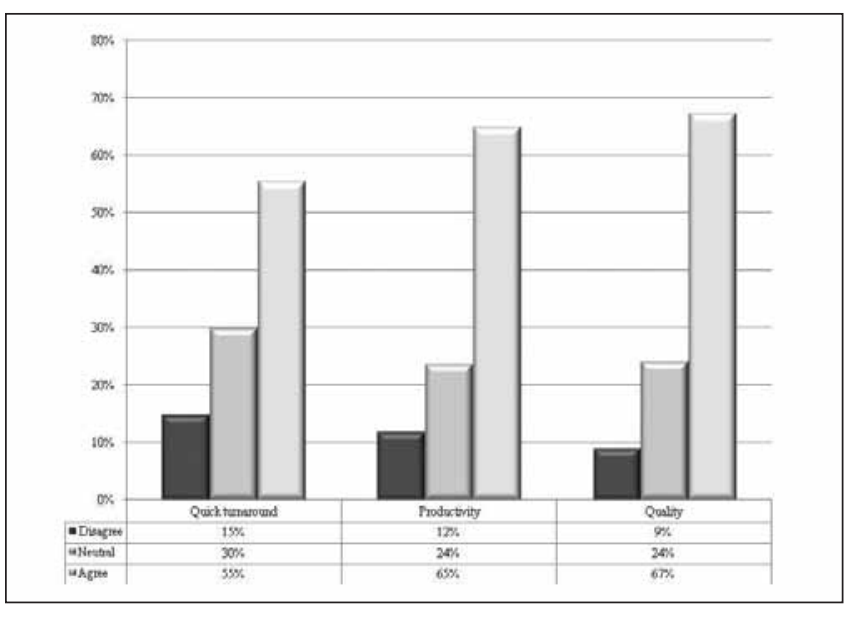

Figure 8. Users' Perceptions of Website Usefulness

majority of users rely on commercial web resources for their academic tasks.

\section{Discussion}

Based on the study's findings, this discussion will first cover the most influential factors first followed by the least influential elements in designing a university library website. First, the most influential factors for website designers are expert opinions and consultations with other divisions within the library. These may be the most important factors because relying on experts allows designers to discover users' needs while saving costs. Web designers also consider input from webmasters and web committees. Coercive and mimetic forces are also highly significant factors affecting web designers. The university library is a subset of the university, and thus, designers may need to align themselves with university policy. Also, designers can claim legitimacy by imitating other successful university websites, thereby securing necessary resources and support for website creation; however, web designers are much less likely to imitate commercial websites. This finding is consistent with existing reports that organizations imitate other successful organizations' managerial practices that are within the same industry category. ${ }^{38}$

The least influential website creation factors are supervisors' knowledge, which in turn impacts low budget allocations, and web designers' technical training. This finding is consistent with successful technology deployment literature that shows supervisors' technical knowledge is highly correlated with budget allocations. ${ }^{39}$ The lack of training for web designers does not appear to be improved since the last study, which was conducted in 2001; ${ }^{40}$ library 


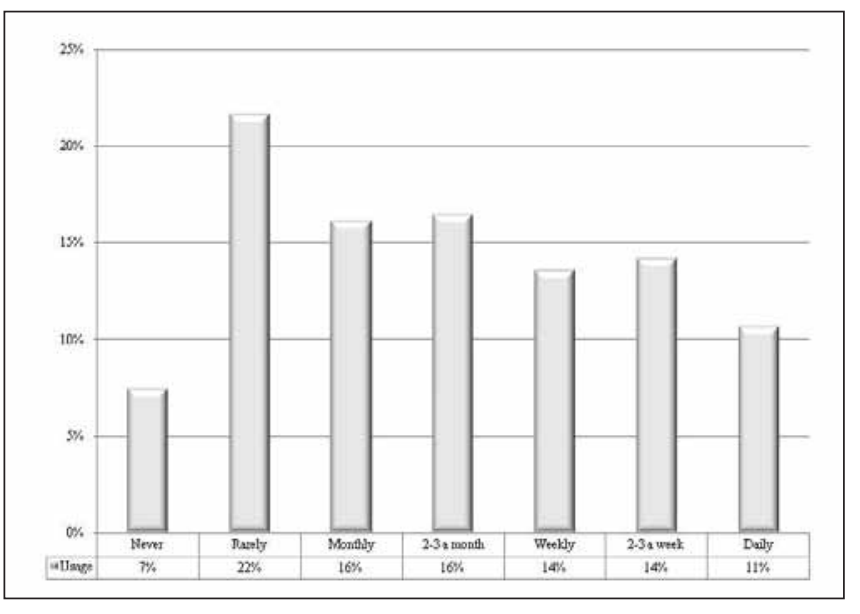

Figure 9. Frequency of Visits to University Library Websites

web designers are usually self-taught rather than formally trained. ${ }^{41}$ One promising finding, though, is that despite the relatively low technical knowledge held by supervisors, the respondents tend to rank highly when it comes to their perceptions of the importance of technology.

Compared with other institutional forces, normative force is relatively low. This kind of institutional force is higher at the early stage of technology adoption. In other words, the majority of universities have already launched their websites and have established rules and policies, so libraries are already past this stage. Also, input from user surveys is relatively low. This may be because it is very costly, and they have other sources to turn to such as other universities' successful websites.

Website success evaluations by web designers and users show discrepancies. Overall, web designers evaluate their websites to be highly successful, while user ratings offer a different picture. This incongruity is a red flag in terms of ULWR usage. The majority of users report that they turn to commercial websites more than ULWR, and one-third never or rarely visit the university website. The disparity of the success between web designers and users may be attributed to the sources of information that website designers rely on. More specifically, existing studies report that input from experts and website committees is incongruent with what users really want, while feedback from focus groups can assist in understanding users' needs. ${ }^{42}$

\section{Conclusions}

This study investigates the factors that website designers consider when designing university library websites.

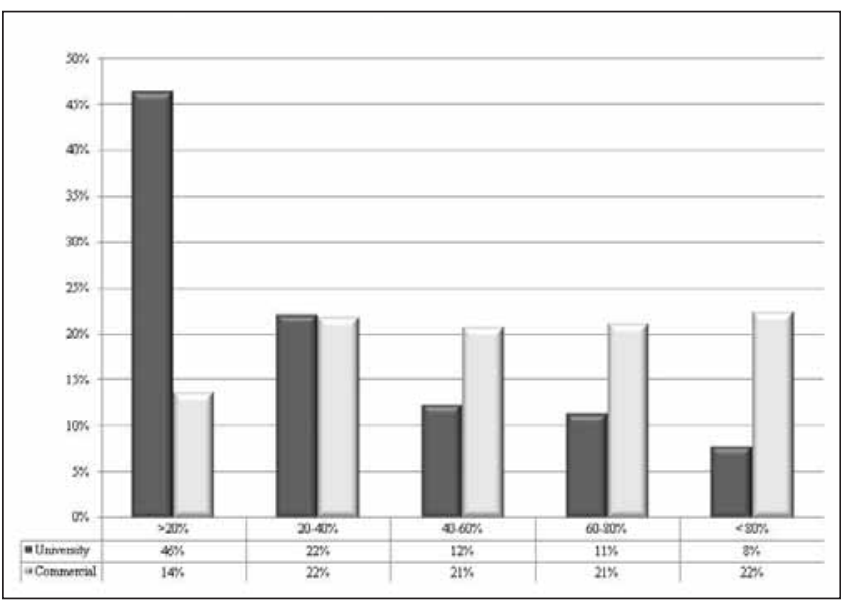

Figure 10. University Library vs. Commercial Website

From a utilitarian perspective, web designers primarily need to consider the ability of the website to meet users' needs. Usefulness again needs to be evaluated by users. According to user assessments ULWR are somewhat satisfactory but not strong enough to rely heavily on for academic projects. It is an alarming fact that users use commercial website resources at a much higher rate than ULWR. This is somewhat disturbing given that web designers strive to provide good services to users, and libraries have invested massive resources into providing online services.

This study has implications for academia and practitioners. For academia, there has been sparse research on web design studies from a designer standpoint. It may be because of difficulties in collecting data directly from website designers. From this line of research, this study enhances the understanding of what factors influence university web design. Although university websites may be deemed successful, information managers should discover why the majority of users turn to commercial websites for their academic projects. Without addressing this problem, the existence of library websites may be compromised. Although there is evidence that libraries consider user input, it may not accurately represent all user populations because only extremely satisfied or extremely dissatisfied users tend to provide feedback; ${ }^{43}$ consequently, a regular survey may facilitate the utilization of ULWR. Finally, supervisors' technical knowledge is found to be low. This problem may be alleviated as time goes on because new generations are more aware of the importance of technology. In the meantime, web designers are encouraged to actively communicate with supervisors about the value of the utilization of technology and seek more financial support.

This study's data have some limitations. Although the 
author tried to increase responses using various means, the number of responses does not allow one to use a sophisticated analytical technique such as regression. This study includes academic libraries with a web designer within the library; as a consequence, libraries without a web designer are not included. It is recommended to collect data from both groups and compare those with a designer (resource rich) and without a designer (resource poor), and discover underlying patterns of the factors impacting website designs and offer implications for academia and managers.

\section{References}

1. D. V. Parboteeah, J. S. Valacich and J. D. Wells, "The Influence of Website Characteristics on a Consumer's Urge to Buy Impulsively," Information Systems Research 20, no. 1 (2009): 60-78; M-H. Huang, "Designing Web Site Attributes to Induce Experiential Encounters," Computers in Human Behavior 19 (2003): 425-42.

2. Y-M. Kim, "The Adoption of University Library Web Site Resources: A Multigroup Analysis," Journal of the American Society for Information Science \& Technology 61, no. 5 (2010): 978-93; O. Nov and C. Ye, “Users' Personality and Perceived Ease of Use of Digital Libraries: The Case for Resistance to Change," Journal of the American Society for Information Science $\mathcal{E}$ Technology 59 (2008): 845-51; N. Park et al., "User Acceptance of A Digital Library System in Developing Countries: An Application of the Technology Acceptance Model" International Journal of Information Management 29, no. 3 (2009): 196-209.

3. W. Hong et al., "Determinants of User Acceptance of Digital Libraries: An Empirical Examination of Individual Differences and System Characteristics," Journal of Management Information Systems 18, no. 3 (2001-2): 97-124.

4. Parboteeah, Valacich and Wells, "The Influence of Website Characteristics; J. Palmer, "Web Site Usability, Design, and Performance Metrics," Information Systems Research 13, no. 2 (2002): 151-67.

5. C. Burton, "Library Web site User Testing," Collect $\mathcal{E}$ Undergraduate Libraries 9, (2002): 10; S. Ryan, "Library Web Site Administration: A Strategic Planning Model for the Smaller Academic Library," Journal of Academic Librarianship 29, no. 4 (2003): 207-18; Y-H Chen, C.A. Germain., and H. Yang, "An Exploration into the Practices of Library Web Usability in ARL Academic Libraries," Journal of the American Society for Information Science and Technology 60, no. 5 (2009): 953-68.

6. M-H Huang, "Designing Web Site Attributes to Induce Experiential Encounters," Computers in Human Behavior 19 (2003): 425-42.

7. W. R. Scott, Institutions and Organizations (Thousand Oaks, Calif.: Sage Publications, Inc, 1995); P. DiMaggio and W. Powell, "The Iron Cage Revisited: Institutional Isomorphism and Collective Rationality in Organizational Fields," American Sociological Review 48 (1983): 147-60.

8. W. R. Scott, Institutions and Organizations; H. Haverman, "Follow the Leader: Mimetic Isomorphism and Entry into New Markets," Administrative Science Quarterly 38, no. 4 (1993): 593-627; M. W. Chiasson and E. Davidson," Taking Industry
Seriously in Information Systems Research," MIS Quarterly 29, no. 4 (2005): 591-605.

9. Scott, Institutions and Organizations; DiMaggio and Powell, "The Iron Cage Revisited"; H. Haverman, "Follow the Leader: Mimetic Isomorphism and Entry into New Markets," Administrative Science Quarterly 38, no. 4 (1993): 593-627.

10. Scott, Institutions and Organizations.

11. K. Lee, Dinesh Mirchandani, and Xinde Zhang, "An Investigation on Institutionalization of Web Sites of Firms," The DATA BASE for Advances in Information Systems 41, no. 2 (2010): $70-88$.

12. Lee, Mirchandani, and Zhang, "An Investigation on Institutionalization of Web Sites of Firms."

13. R. Raward, "Academic Library Website Design Principles: Development of a Checklist," Australian Academic \& Research Libraries 32, no. 2 (2001): 123-36.

14. Y-M. Kim, An Investigation of the Effects of IT Investment on Firm Performance: The Role of Complementarity (Saarbrucken, Germany: VDM Verlag, 2008); P. Weill, "The Relationship between Investment in Information Technology and Firm Performance: A Study of the Valve Manufacturing Sector," Information Systems Research 3, no. 4 (1992): 307-33.

15. A. Lederer and V. Sethi, "The Implementation of Strategic Information Systems Planning Methodologies," MIS Quarterly (1988): 445-461; J. Thong, C. Yap, and K. Raman, "Top Management Support, External Expertise and Information Systems Implementation in Small Business," Information Systems Research 7, no. 2 (1996): 248-67; M. Earl, "Experiences in Strategic Information Systems Planning," MIS Quarterly (1993): 1-24; A. Boynton and R. Zmud, "Information Technology Planning in the 1990's: Directions for Practice and Research," MIS Quarterly 11, no. 1 (1987): 59-72.

16. S. Jarvenpaa and B. Ives, "Information Technology and Corporate Strategy: A View from the Top," Information Systems Research 1, no. 4 (1990): 351-76.

17. Chen, Germain, and Yang, "An Exploration into the Practices of Library Web Usability in ARL Academic Libraries."

18. Ibid.

19. J. Veldof and S. Nackerud, "Do You Have the Right Stuff? Seven Areas of Expertise for Successful Web Site Design in Libraries," Internet Reference Services Quarterly 6, no. 1 (2001): 20.

20. Chen, Germain, Yang, "An Exploration into the Practices of Library Web Usability in ARL Academic Libraries"; R. Raward, "Academic Library Website Design Principles: Development of a Checklist," Australian Academic \& Research Libraries 32, no. 2 (2001): 123-36; J. Bobay et al., “Working With Consultants to Test Usability: The Indiana University Bloomington Experience," in Usability Assessment of Library-Related Web Sites: Methods and Case Studies, ed. N. Campbell (Chicago: ALA, 2002): 60-76; H. King and C. Jannik, "Redesigning for Usability: Information Architecture and Usability Testing for Georgia Tech Library's Website," OCLC Systems E Services 21, no. 3 (2005): 235-43.

21. J. H. Spyridakis, J. B. Barrick, and E. Cuddihy, "InternetBased Research: Providing a Foundation for Web-Design Guidelines," IEEE Transactions on Professional Communication 48, no. 3 (2005): 242-60; T. A. Powell, Web Design: The Complete Reference (Berkeley, Calif.: Osborne/McGraw-Hill, 2002).

22. Powell, Web Design.

23. R. Tolliver, D. Carter, and S. Chapman, "Website Redesign and Testing with a Usability Consultant: Lessons Learned," OCLC Systems \& Services 21, no. 3 (2005): 156-66; L. VandeCreek, 
"Usability Analysis of Northern Illinois University Libraries' Website: A Case Study," OCLC Systems \& Services 21, no. 3 (2005): 181-92.

24. Spyridakis, Barrick, and Cuddihy, "Internet-Based Research."

25. B. Bailey, "Heuristic Evaluations vs. Usability Testing," UI Design Update Newsletter (2001), http:/ / www.humanfactors .com/downloads/jan01.asp (accessed June 10, 2011).

26. Powell, Web Design.

27. Chen, Germain, and Yang, "An Exploration into the Practices of Library Web Usability in ARL Academic Libraries."

28. K.A. Saeed, Y. Hwang, and V. Grover, "Investigating the Impact of Web Site Value and Advertising on Firm Performance in Electronic Commerce," International Journal of Electronic Commerce 7, no. 2 (2003): 119-41.

29. L. Manzari and J. Trinidad-Christensen, "User-Centered Design of a Web Site for Library and Information Science Students: Heuristic Evaluation and Usability Testing," Information Technology E Libraries 25, no. 3 (2006): 163-69.

30. E. Abels, M. White, and K. Hahn, "Identifying User-Based Criteria for Web Pages," Internet Research 7, no. 4 (1997): 252-56.

31. L. VandeCreek, "Usability Analysis of Northern Illinois University Libraries' Website: A Case Study," OCLC Systems $\mathcal{E}$ Services 21, no. 3 (2005): 181-92; M. Ascher, H. Lougee-Heimer, and D. Cunningham, "Approaching Usability: A Study of an Academic Health Sciences Library Web Site," Medical Reference Services Quarterly 26, no. 2 (2007): 37-53; B. Battleson, A. Booth and J. Weintrop, "Usability Testing of an Academic Library Web Site: A Case Study," Journal of Academic Librarianship 27, no. 3 (2001): 18898; G. H. Crowley et al., "User Perceptions of the Library's Web Pages: A Focus Group Study at Texas A\&M University," Journal of Academic Librarianship 28, no. 4 (2002): 205-10; B. Thomsett-Scott and F. May, "How May We Help You? Online Education Faculty Tell Us What They Need from Libraries and Librarians," Journal of Library Administration 49, no. 1/2 (2009): 111-35; D. Turnbow et al.,
"Usability Testing for Web Redesign: A UCLA Case Study," OCLC Systems E Services 21, no. 3 (2005): 226-34; J. Ward, "Web Site Redesign: The University of Washington Libraries' Experience," OCLC Systems \& Services 22, no. 3 (2006): 207-16.

32. Chen, Germain, and Yang, "An Exploration into the Practices of Library Web Usability in ARL Academic Libraries."

33. Ibid.

34. Kim, "The Adoption of University Library Web Site Resources."

35. Ibid.

36. Ibid.

37. Y-M. Kim, "Validation of Psychometric Research Instruments: The Case of Information Science," Journal of the American Society for Information Science \& Technology 60, no. 6 (2009): 1178-91.

38. H. Haverman, "Follow the Leader: Mimetic Isomorphism and Entry into New Markets," Administrative Science Quarterly 38, no. 4 (1993): 593-627.

39. T. Teo and J. Ang, "An Examination of Major IS Planning Problems," Information Journal of Information Management 21 (2001): 457-70.

40. R. Raward, "Academic Library Website Design Principles: Development of a Checklist," Australian Academic \& Research Libraries 32, no. 2 (2001): 123-36.

41. Ibid.

42. Chen, Germain, and Yang, "An Exploration into the Practices of Library Web Usability in ARL Academic Libraries"; Powell, Web Design; B. Bailey, "Heuristic Evaluations vs. Usability Testing," UI Design Update Newsletter (2001), http:// www.humanfactors.com/downloads/jan01.asp (accessed June 15, 2011).

43. T. Hennig-Thurau et al., "Electronic Word-of-Mouth Via Consumer-Opinion Platforms: What Motivates Consumers to Articulate Themselves on the Internet?" Journal of Interactive Marketing 18, no. 1 (2004): 38-52. 